\title{
Microstrip Antenna for WLAN Application Using Probe Feed
}

\author{
Amit Kumar ${ }^{1}$, Prof.P.R.Chadha ${ }^{2}$ \\ ${ }^{I}$ (Electronics \& Communication Engneering, Delhi Technological University, Delhi,India) \\ ${ }^{2}$ (Electronics \& Communication Engneering, Delhi Technological University, Delhi,India)
}

\begin{abstract}
Microstrip patch antennas have been widely used in a various useful applications, due to their low weight and low profile, conformability, easy and cheap realization. A low profile patch antenna for WLAN application is proposed in this paper. This proposed antenna is made by using the probe feeding and aperture coupled feeding methods. This antenna is designed in order to improve the impedance bandwidth and obtain the circular polarization without using truncated corners in patch. The impedance bandwidth will be increased by making slots onto the patch. This unequal parallel slots patch antenna is the modified structure of $E$ patch antenna and U slot Patch antenna. This patch antenna provides a bandwidth of around 16.4\% with 1.5 VSWR. The simulation process has been done through high frequency structure simulator (HFSS). The properties of antenna such as bandwidth, S parameter, VSWR have been investigated. This paper also aims at comparing between different feeding methods.
\end{abstract}

Keywords - Aperture coupling, HFSS,Microstrip patch antenna, Probe feed, Return Loss, VSWR (Voltage Standing Wave Ratio).

\section{INTRODUCTION}

A microstrip antenna consists of a very thin metallic patch placed on conducting ground plane, separated by a dielectric substrate . A microstrip patch consists of a radiating patch of any planar geometry (e.g. Circle, square, Ellipse, ring and rectangle) on one side of a dielectric material substrate and a ground plane on the other side. Microstrip antennas have numerous advantages such as lightweight, low profile, easy fabrication and simple modeling. They can be designed to operate over a large range of frequencies (1- $40 \mathrm{GHz})$ and easily combine to form linear or planar arrays. It can generate linear, dual, and circular polarizations. The microstrip antenna has different feeding techniques like probe fed, aperture coupled, proximity and insert feed. The substrate dielectric constant used for microstrip antenna generally low (typically $~ 2.5$ ) to reduced fringing field but for less critical applications. The proposed antenna is designed for $2.45 \mathrm{GHz}$ frequency with $\mathrm{E}$ shaped patch and $\mathrm{U}$ slot patch . The proposed antenna is made by using probe fed and aperture coupled fed and simulated by HFSS'11. A typical patch antenna is Shown in Figure 1.1

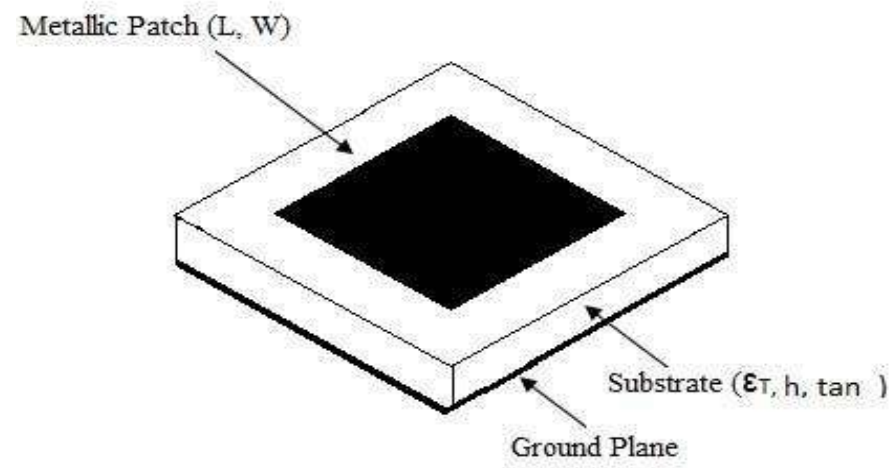

Fig No-1.1 Microstrip Antenna

\subsection{Coaxial Probe Feed}

\section{TYPES OF FEED}

Coaxial feed is the simplest feed for microstrip antennas. In this, an inner conductor of coaxial line is attached to the radiating patch while outer conductor is connected to ground plane. The structure of coaxial probe feed is display in figure 2.1. It has spurious radiation because the radiating and feeding systems are disposed on two sides of ground plane and shielded from each other. The proposed antenna is designed for $2.45 \mathrm{GHz}$ frequency for WLAN application. This antenna has patch size $(\mathrm{L} \mathrm{X} \mathrm{W}) \mathrm{mm}$ with ${ }_{\mathrm{r}}=2.2$ dielectric substrate. The serious limitation of microstrip antenna is narrow bandwidth, which is usually few percent $(<1 \%)$. 


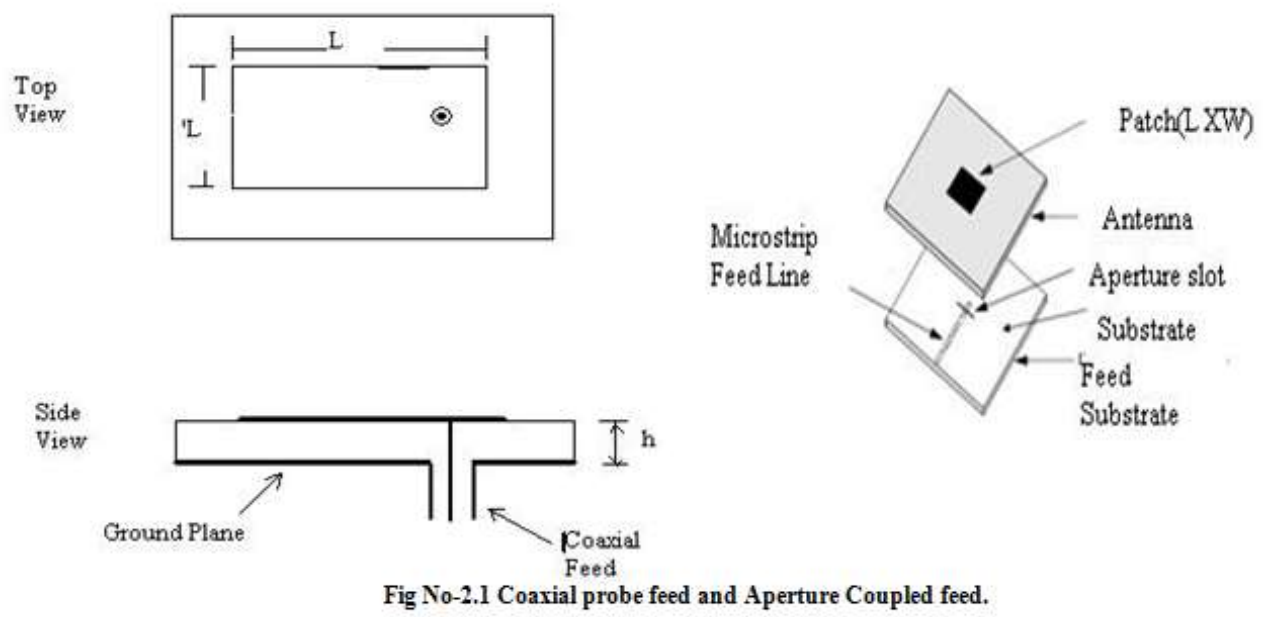

\subsection{Aperture Coupled Feed}

In this the radiating patch is etched on the top of the antenna substrate and feed line is etched on the bottom of substrate. The thickness and dielectric constants of these two substrates may thus be chosen independently to optimize the distinct electrical functions of radiation and circuitry. The basic structure of aperture coupled microstrip antenna is shown in figure 2.1.

\section{ANTENNA GeOMETRY For Probe FEed}

In this paper, We used various patch shapes like U slot, E Shaped and some another unequal shapes slots in rectangular patch with different dielectric constants. But the best result is provided by unequal $\mathrm{E}$ shaped slot with rectangular patch.

\subsection{E Shaped Rectangular Patch Antenna}

In this paper, the well known technique of an E shaped patch used for a wide band width. An E-shaped patch antenna is easily formed by cutting two slots from a rectangular patch [4]. By cutting the slots from a patch, gain and bandwidth of microstrip antenna can be enhanced. For this proposed antenna, size of ground plane is (L X W) $76 \times 88 \mathrm{~mm}$ and thickness of dielectric substrate is $6.7 \mathrm{~mm}$ with $\mathrm{r}=2.2$.The geometry of $\mathrm{E}$ shaped patch antenna is shown in table 1.1

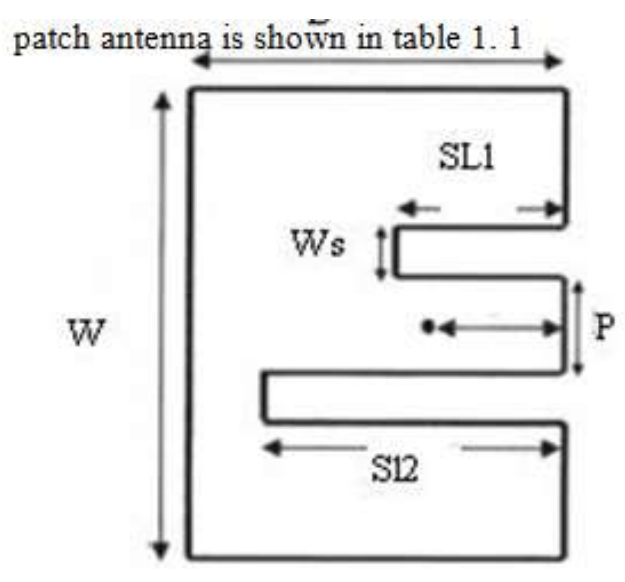

\begin{tabular}{|l|l|l|l|l|l|l|l|l|}
\hline W & L & Ws & SL1 & SL2 & P & F & H & fr \\
\hline 48 & 36 & 6.3 & 30 & 30 & 11.4 & 9 & 6.7 & 2.2 \\
\hline
\end{tabular}

TABLE 1. The Dimensions of Patch In MM

Figure 3.1 Geometry of Unequal E Shaped Patch Antenna

This E shaped patch antenna provides a $7.8 \%(2.34-2.53 \mathrm{GHz})$ impedance bandwidth with $5.8 \mathrm{~dB}$ gain. The figure 3.2 (a) and 3.3 (a) is shown the return loss in $\mathrm{dB}$ and smith chat for equal size of slots in patch. The $\mathrm{E}$ shaped patch antenna is designed here, has $-33 \mathrm{~dB}$ return loss. The gain curve is shown in figure 3.4 (a). This antenna provides good VSWR ( 1.02).

When the slot $\mathrm{S}_{\mathrm{L} 1}$ gets shorter, it forms the unequal slots $\mathrm{E}$ shaped patch antenna as shown in fig 3.1 [5]. This unequal $\mathrm{E}$ shapedpatch antenna provides circular polarization. This antenna provides $16.4 \%(2.15 \mathrm{GHz}-$ 
$2.53 \mathrm{GHz}$ ) impedance bandwidth at $-10 \mathrm{~dB}$ return loss and $6 \mathrm{~dB}$ gain.

\section{Antenna Design Results}

The figures 4.1, 4.2 and 4.3 are showing the return loss in $\mathrm{dB}$ and smith chat for unequal length of slots in patch. The E shaped patch antenna designed here has near about (-32) dB return loss. The gain curve is shown in figure 4.4 , this antenna provides good VSWR ( 1.5). Table 2 shows simulated results.

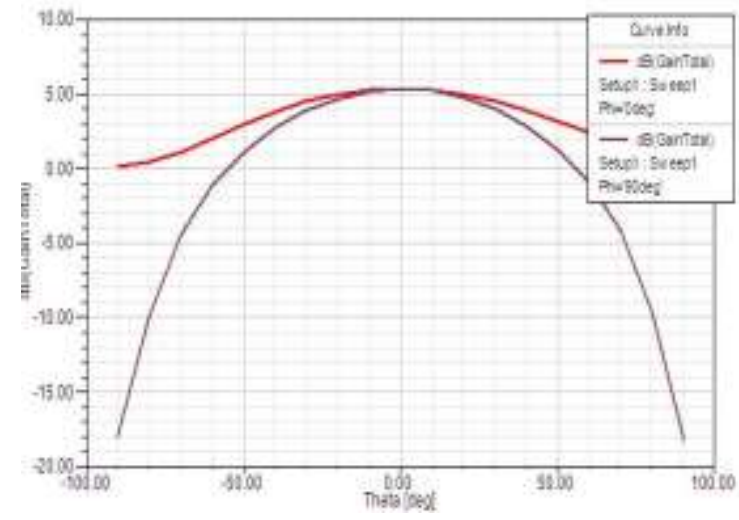

(a)

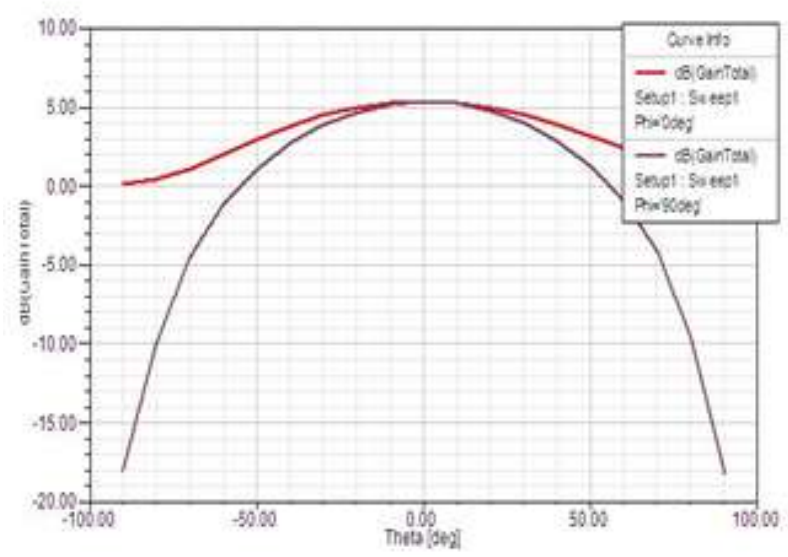

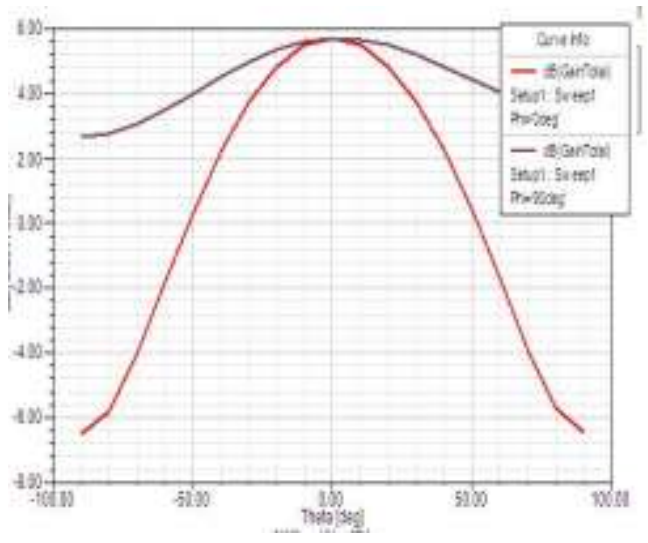

(b)

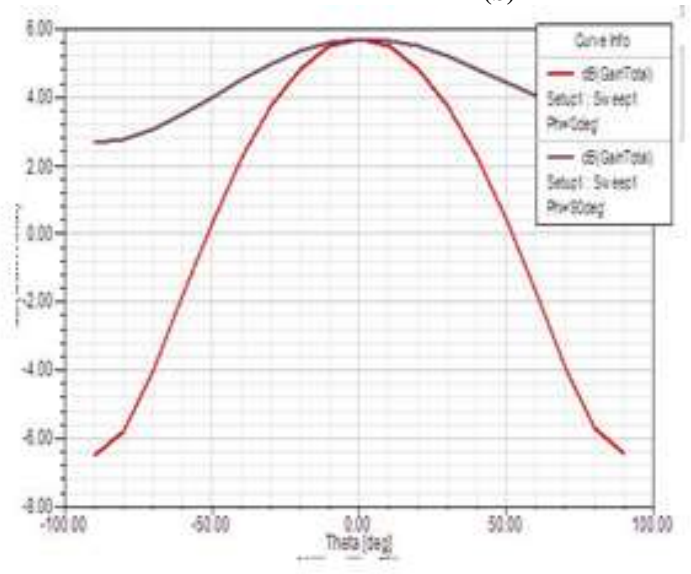

(c)

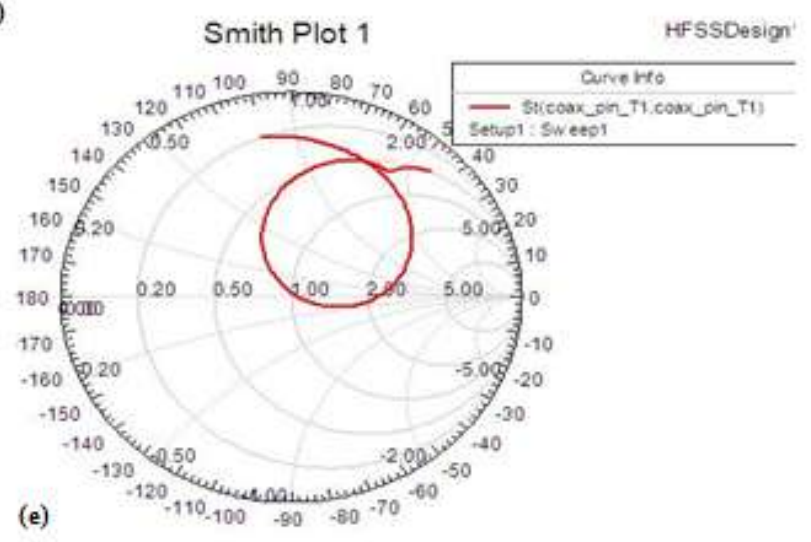

(d)

Fig No-4.1 a, b, c, d, e, Antenna Design Results.

\begin{tabular}{|l|l|l|l|l|}
\hline Patch Shape & Frequency & Gain & Return Loss & Bandwidth \\
\hline E Shaped Patch & $2.45 \mathrm{GHz}$ & $\mathbf{5 . 6 \mathrm { dB }}$ & $\mathbf{- 3 3 \mathrm { dB }}$ & $\mathbf{7 . 8} \%$ \\
\hline Unequal arms E Shaped Patch & $2.43 \mathrm{GHz}$ & $6 \mathrm{~dB}$ & $-31.2 \mathrm{~dB}$ & $16.4 \%$ \\
\hline
\end{tabular}

TABLE 2. Simulated Results For Probe Feed Patch Antenna 


\section{Conclusion}

An E shaped microstrip patch antenna is designed and by observing the simulated results we can say that antenna is resonating at $2.45 \mathrm{GHz}$.which is most suited for WLAN application .From the above obtained results we can say antenna is resonating at $2.45 \mathrm{GHz}$, and antenna will be used in WLAN application. The design is simulated in HFSS.

A small-size Microstrip antenna for WLAN Application using probe feed and aperture feed is proposed and successfully implemented. From the comparative study of different configurations of feeding techniques, it is concluded that unequal slot in patch provides a bandwidth of $16.4 \%$ with $6 \mathrm{~dB}$ gain and near about 1.06 VSWR and an aperture coupled feed microstrip antenna provides a bandwidth of around 24\% with 1.04 VSWR. This proposed microstrip antenna enhanced the impedance bandwidth and provides good matching. This antenna is simulated by HFSS' 11

\section{Journal Papers:}

\section{REFERENCES}

[1] K. F. LeE1, K. M. Lu, K. M. Ma, AND S. L. S. Yang1, "ON the Use of U-SLOtS in the Design of Dual-AND TRIPLE-Band Patch ANTENNAS” IEEE ANTENNAS AND Propagation MagaZine, Vol. 53, No.3, June 2011.

[2]. Qinjiang Rao, Tayeb A. Denidni, "A New Aperture Coupled Microstrip Slot Antenna" IEEE Transactions on Antennas and Propagation, Vol.53, No. 9, September 2005.

[3]. .Subodh Kumar Tripathi1, Vinay Kumar2, "E-Shaped Slotted Microstrip Antenna with Enhanced Gain for Wireless communication" International Journal of Engineering Trends and Technology- July to Aug Issue 2011.

[4] D. M. Pozar, "Microstrip antenna aperture-coupled to a microstripline," Electron. Lett., vol. 21, no. 2, pp. 49-50, Jan. 1985.

[5]. Antenna Theory, C.Balanis, Wiley, $2^{\text {nd }} \quad$ edition (1997), Chapter 14. ISBN 0-471-59268-4.

[6]. Ahmed Khidre, Kai Fang Lee, Fan Yang, and Ate' Eisherbeni "Wideband Circularly Polarized E-Shaped Patch Antenna for Wireless Applications" IEEE Antennas and Propagation Magazine, Vol. 52, No.5, October 2010.

[7]. Hall, P. S. Wood, C and Garrett, C, _Wide bandwidth microstripcantennas for circuit integratio", Electron. Lett. , 15, pp. 458-460, 1979.

[8]. Pues H. F. and Van De Capelle A. R. "Impedance-matching of microstrip resonator antennas", Proceedings of the North American Radio Science Meeting, Quebec, p. 189, 1980.

[9]. Ravi Kant and D.C.Dhubkarya, "Design \& Analysis of H-Shape Microstrip Patch Antenna", publication in the _Global Journal of Research in Engineering, Vol. 10 Issue 6 (Ver. 1.0), pp. 26-29, Nov. 2010.

[10]. Punit.S.Nakar, "Design of a Compact microstrip Patch Antenna for use in Wireless /Cellular Devices. Florida University,2004. 